\title{
Low-Temperature Alkali-Anthraquinone Pretreatment of Wheat Straw: Gradual Dissolution of Lignin and Carbohydrate Retention in Pretreated Solids
}

\author{
Lilong Zhang and Keli Chen*
}

This paper presents a comprehensive study of wheat straw that was alkalipretreated with $\mathrm{NaOH}$ loadings from 60 to $220 \mathrm{mg} \mathrm{NaOH} / \mathrm{g}$ dry straw and a $0.5 \%$ anthraquinone (AQ) loading at $90{ }^{\circ} \mathrm{C}$ for 1,2 , and $3 \mathrm{~h}$. Images of the residual solids were taken with a scanning electron microscope. A full compositional analysis of the raw material and residual solids, yield of compounds dissolved in the black liquor (BL), and molecular weight (Mw) after the different pretreatments were presented to track the dissolution process of lignin and carbohydrates. The ratio of the lignin fraction to carbohydrates dissolved in the BL was used for an analysis of the reaction selectivity. The cellulose retained $90 \%$ of the carbohydrates in the pretreated straw, while $75 \%$ of the lignin was dissolved in the BL gradually with an intermediate value of $M_{w}$. Low-molecular weight lignin $\left(M_{w} \sim 1800\right.$ and degree of polymerization 1.05) was dissolved out with the $60 \mathrm{mg}$ $\mathrm{NaOH} / \mathrm{g}$ dry straw loading. When the $\mathrm{NaOH}$ loading was increased to 220 $\mathrm{mg} \mathrm{NaOH} / \mathrm{g}$ dry straw, the $M_{\mathrm{w}}$ of the lignin was 4300 to 4700 .

Keywords: Alkali pretreatment; Low temperature; Wheat straw; Lignin; Selective pretreatment

Contact information: Faculty of Chemical Engineering, Kunming University of Science and Technology, Yunnan 650500, China; *Corresponding author: chenkeli_prof@sina.com

\section{INTRODUCTION}

Wheat straw is one of the most abundant and low-cost sources of biomass that is widely distributed around the world. The Food and Agriculture Organization of the United Nations (FAO) has reported that 100 million tons of wheat straw is produced annually in more than 100 countries (FAO 2013). Wheat straw can be used in many areas, such as feeding, composting, and fermentation (Hassanein and Koumanova 2010; Zhan 2010; Baig et al. 2015). Thus, this superior biomass source should be considered a potential future energy and chemical resource. However, this sustainable biomass source is currently being wasted, and the majority of it is burned on the spot in China (Zhang 2008; Zhan 2010). The inefficiency and low economic benefit block the development of new applications and promotion, which is possibly because of its inherent composition and structure.

Lignocellulose is found primarily in plant cell walls. Plant cell walls are complicated natural composites with three major constituents, cellulose, hemicellulose, and lignin. The cellulose in plants is comprised of crystalline $\beta$-1,4-glucans, which accounts for $28 \%$ to $45 \%$ of the dry matter in plants. The crystallinity of cellulose is a key factor that negatively affects biomass digestibility (Duan et al. 2013). The crystalline structure is surrounded by hemicellulose and lignin, which makes it difficult for wheat straw to be hydrolyzed and broken down by chemicals (Mittal et al. 2011). Hemicellulose, which is mostly composed of xylose, arabinose, mannose, and glucuronic acid units, is a diverse group of natural and heterogeneous branched biopolymers (degree of 
polymerization, DP $=80$ to 200) found in plant cell walls. Several applications for the carbohydrate fractions obtained by the fractionation process have been investigated (Gao et al. 2016).

Lignin, as a complex aromatic compound, can be dissolved or removed from lignocellulose with difficulty, which presents a challenge for pulping and dissolution in chemicals (Sewalt et al. 1997). Meanwhile, as the second-most common biopolymer on earth, lignin plays an important role in the production of bio-fuel, bio-materials, and chemicals (Li et al. 2015; Lyckeskog et al. 2016; Zhao et al. 2016; Zhang and Chen 2017). Lignin can be transformed into high value-added chemicals in two ways: degradation into low-molecular weight (LMW) compounds (Sun et al. 2015) or polymerization into highmolecular weight (HMW) compounds (Rios et al. 2014). The degradation of lignin into LMW compounds has yielded practical chemicals such as bio-fuel, phenols, and aromatics (Singh et al. 2014). Applications for HMW lignin include the production of adhesives, carbon fiber, and thermally-stable copolyesters by increasing the DP (Meek et al. 2016). However, because of the complex structure and wide molecular weight distribution, lignin that is isolated from biomass cannot be applied in the previously mentioned applications directly. Therefore, pretreatment is a necessary step to obtain a narrower molecular weight distribution and high-activity lignin, which results in lignin that is better suited for bio-conversion applications.

Thus, it is necessary to develop a pretreatment for making full use of this biomass. Pretreatment can break down the crystal structure of lignocellulose for easier dissolution in chemicals. Also, lignin-enriched products dissolved from lignocellulose could be used for suitable conversion.

Alkali pretreatment is considered to be a promising chemical treatment method because of its low operation cost and reduction of holocellulose degradation (Zhang et al. 2011). Alkali pretreatment mainly effects the degradation of ester bonds and cleavage of glycosidic linkages when the pretreatment is performed above $100^{\circ} \mathrm{C}$ (Srinorakutaral et al. 2013). These effects lead to an increase in the solubility and dissolution of lignin, which causes swelling of the cellulose structure and partial decrystallization of cellulose. However, the drawback of traditional alkali pretreatment is that when collecting lignin from lignocellulosic biomass, polysaccharides, especially hemicellulose and cellulose, are dissolved at high-temperature pretreatment conditions $\left(>100^{\circ} \mathrm{C}\right)$ (Agbor et al. 2011). The addition of anthraquinone (AQ) can oxidize the carbohydrate end groups and mitigate hemicellulose loss via peeling reactions because the carbohydrate acid end groups are more stable in an alkali media. Therefore, AQ is widely used in traditional pulping processes to increase the retention of hemicellulose, which can increase pulp yields and improve the tensile strength (Heitner et al. 2010). However, very few studies on alkali-AQ pretreatment have been done. Karp et al. (2015) studied the alkali-AQ pretreatment of switchgrass with high pretreatment temperatures $\left(>100{ }^{\circ} \mathrm{C}\right)$. It was found that the optimal pretreatment conditions were $154 \mathrm{mg} \mathrm{NaOH} / \mathrm{g}$ dry switchgrass, $130{ }^{\circ} \mathrm{C}$, and $30 \mathrm{~min}$. Li et al. (2012) researched different alkali-based pretreatments of corn stover, including NaOH-AQ, and found that an $\mathrm{NaOH}$-sulfite pretreatment at $140{ }^{\circ} \mathrm{C}$ led to a high lignin removal and carbohydrate recovery with better enzymatic digestibility. However, a study focused on the alkali-AQ pretreatment of wheat straw at low temperatures was unfamiliar to the authors.

Theoretically, alkali pretreatment of wheat straw with AQ at low temperatures could avoid the traditional alkali pretreatment disadvantages. First, alkali pretreatment is generally more effective on agricultural residues and herbaceous crops. The rate of delignification during soda pulping of wheat straw can reach approximately $60 \%$ at $100{ }^{\circ} \mathrm{C}$ 
(Epelde et al. 1998). Second, a low temperature of approximately $90{ }^{\circ} \mathrm{C}$ and the addition of AQ could protect cellulose from degradation. Finally, because lignin removal is markedly increased as the temperature increases above $100{ }^{\circ} \mathrm{C}$ to $130{ }^{\circ} \mathrm{C}$ (Karp et al. 2015), the low temperature could dissolve lignin into the black liquor (BL) at a steady rate.

To investigate the low temperature alkali-AQ pretreatment of wheat straw, the effect of different alkali loadings and pretreatment times on the dissolution of lignin and carbohydrates was studied. This paper presents a comprehensive study of the alkali pretreatment of wheat straw with $\mathrm{NaOH}$ loadings of 60 to $220 \mathrm{mg} \mathrm{NaOH} / \mathrm{g}$ dry straw, 1:5 solid-to-liquor ratio, and a $0.5 \%$ AQ loading at $90{ }^{\circ} \mathrm{C}$ for 1,2 , and $3 \mathrm{~h}$. The compositions of the pretreated straw and fraction of the BL were determined to analyze the dissolution process of wheat straw.

\section{EXPERIMENTAL}

\section{Materials}

Wheat straw was harvested from Jining, Shandong province of China in the summer of 2014. It was cut to 3- to 5-cm lengths and air-dried for $2 \mathrm{~d}$ or more.

\section{Alkali Pretreatment}

The soda-AQ pretreatment of the dry wheat straw pieces $(100 \mathrm{~g})$ was conducted in a 1-L glass beaker, which was heated in a water bath at $90{ }^{\circ} \mathrm{C}$ with a 30 -min heat ramp. The $\mathrm{NaOH}$ loadings were varied from 60 to $220 \mathrm{mg} \mathrm{NaOH} / \mathrm{g}$ dry straw, and the AQ loading was held constant at $0.5 \%(\mathrm{w} / \mathrm{w})$ by dry wheat straw with a 1:5 solid-to-liquor ratio. To ensure full contact with the $\mathrm{NaOH}$ solution, the wheat straw was mixed well before it was poured into the glass beaker and the beaker was shaken every half hour. At the end of each pretreatment, the beakers were removed from the water bath and rapidly cooled in cold tap water. The BL was separated by squeezing the soaked straw, and then the residue was thoroughly washed with $90{ }^{\circ} \mathrm{C}$ distilled water until the wash water was clean.

\section{Scanning Electron Microscopy (SEM)}

Imaging with scanning electron microscopy (VEGA3-SBH, TESCAN) was performed. Samples were air-dried prior to imaging and mounted on aluminum stubs using conductive carbon tape. The stubs were then sputter-coated with approximately $10 \mathrm{~nm}$ of gold-sputter coater (SBC-12,KYKY Technology Co., Ltd, Beijing, China). The imaging was performed with a beam accelerating voltage of $10 \mathrm{kV}$.

\section{Crystallinity Measurements}

To examine and compare the crystalline structure of both the untreated and alkaline-treated samples, X-ray diffraction (XRD) was performed on an Empyrean diffractometer (PANalytical B.V, Almelo, Holland) with $\mathrm{CuK} \alpha$ radiation that had a wavelength $(\lambda)(\mathrm{K} \alpha 1)$ of $0.15406 \mathrm{~nm}$ generated at $40 \mathrm{kV}$ and $40 \mathrm{~mA}$. The samples were dried in a vacuum oven with $\mathrm{P}_{2} \mathrm{O}_{5}$ at $35{ }^{\circ} \mathrm{C}$ for $48 \mathrm{~h}$. The scans were obtained from $2 \theta$ values of $10^{\circ}$ to $90^{\circ}$ at a scanning speed of $1^{\circ}$ per min. The crystallinity (CI) of the cellulose samples was calculated according to the peak deconvolution method with the ratio between the area of the crystalline contribution and total area, as described by Goikhman et al. (1992) and shown below as Eq. 1, 


$$
\mathrm{CI}=1-\frac{\text { Aam }}{\text { Asimple }}=1-\frac{\int_{2 \theta 1}^{2 \theta 2} \mathrm{I} \operatorname{lam} \mathrm{d} 2 \theta}{\int_{2 \theta 1}^{2 \theta 2} I_{\mathrm{sample}} \mathrm{d} 2 \theta}
$$

where $A_{\mathrm{am}}$ is the area under the amorphous curve $\left(^{\circ}\right), A_{\text {sample }}$ is the area under the sample intensity curve $\left(^{\circ}\right), 2 \theta_{1}=13.5^{\circ}$, and $2 \theta_{2}=49.5^{\circ}$.

\section{Fractionation of Lignin and Hemicellulose from the Black Liquor (BL)}

The scheme for the fractionation of BL is illustrated in Fig. 1. The BL was first acidified with $12 \%(\mathrm{w} / \mathrm{w})$ sulfuric acid until a $\mathrm{pH}$ of 8.5 was achieved for the removal of $\mathrm{SiO}_{2}$ through centrifugation, and then the $\mathrm{pH}$ was adjusted to 2.0 for the precipitation of the crude lignin, which was named $\mathrm{C} 1$. The water phase was treated with the following steps: (1) precipitated with $\mathrm{Ba}(\mathrm{OH})_{2}$ to get rid of $\mathrm{SO}_{4}{ }^{2-}$; (2) centrifuged at $8000 \mathrm{rpm}$ for 20 min, and then the supernatant was dialyzed with a dialysis bag (MD of 55 to 2.0) to remove molecules and ions less than 2000 in molecular weight. The residue was freeze-dried as the water was solubilized and concentrated to approximately $100 \mathrm{~mL}$ at a reduced pressure; (3) the carbohydrate fractions were obtained from the freeze-dried concentrated liquor, which was named $\mathrm{C} 2$.

$$
\mathrm{Y}_{\text {lignin }}(\%)=\frac{\mathrm{W}_{\mathrm{C} 1}}{\mathrm{~W}_{\mathrm{BL}}} \times 100(\%) \quad \mathrm{Y}_{\text {carbonhydate }}(\%)=\frac{\mathrm{W}_{\mathrm{C} 2}}{\mathrm{~W}_{\mathrm{BL}}} \times 100(\%) \quad f=\frac{\mathrm{Y}_{\text {lignin }}}{\mathrm{Y}_{\text {carbonhydate }}} \times 100
$$

In Eq. $2, W_{\mathrm{C} 1}$ is the oven-dry weight of freeze-dried $\mathrm{C} 1(\mathrm{~g}), W_{\mathrm{C} 2}$ is the oven-dry weight of freeze-dried $\mathrm{C} 2(\mathrm{~g})$, and $W_{\mathrm{BL}}$ is the oven-dry weight of the $\mathrm{BL}(\mathrm{g})$

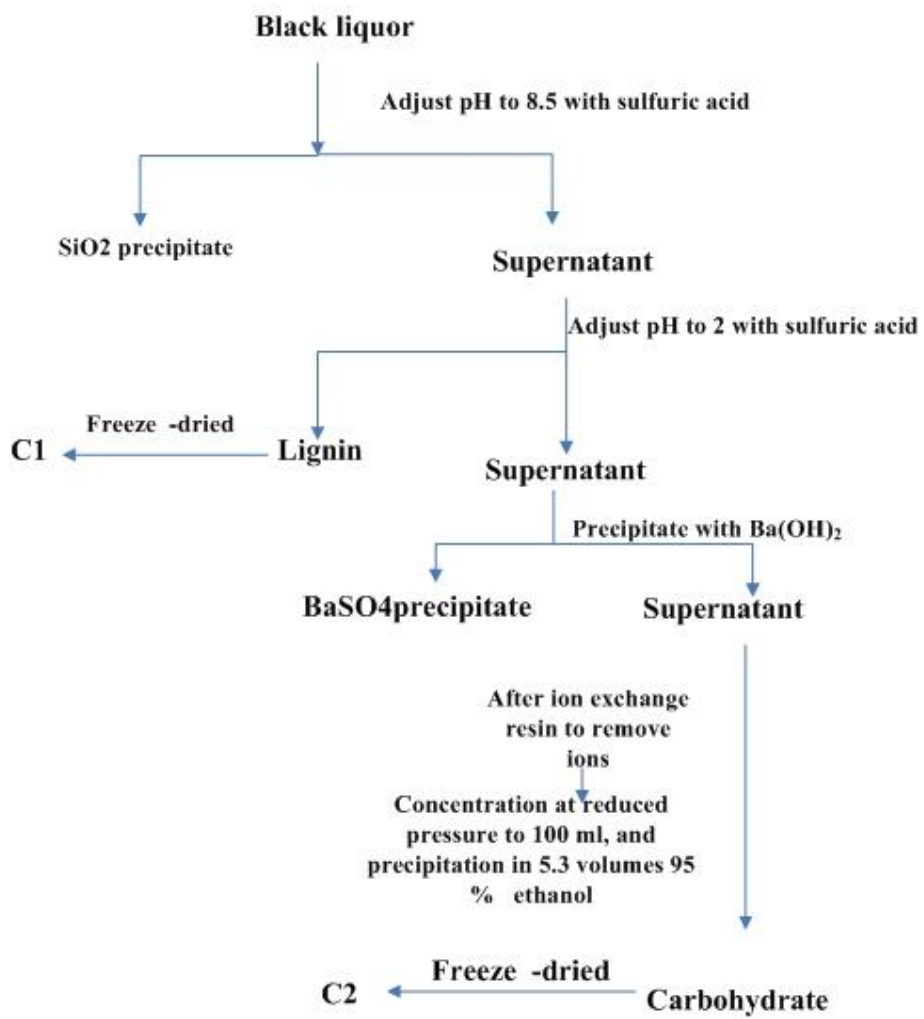

Fig. 1. Scheme for the fractionation of lignin and hemicellulose from the BL 


\section{Molecular Weight Analysis}

Gel permeation chromatography (GPC) was used to determine the molecular weights of the obtained hemicellulose and lignin. GPC was performed on a Waters 1525 binary HPLC pump with a Waters 717 plus auto-sampler, Waters 2414 refractive index detector, and a Breeze (V3.3) GPC work station (Waters, Milford, USA). Prior to the analysis, the lignin and other organic samples included in $\mathrm{C} 1$ were dissolved in tetrahydrofuran (THF), while the hemicellulose in C2 was dissolved in water. The eluent flow was $1 \mathrm{~mL} / \mathrm{min}$, and the system was maintained at $35{ }^{\circ} \mathrm{C}$ during the analysis. Glucan and polystyrene were used as reference substances for hemicellulose and lignin, respectively.

\section{Component Analysis of the Pretreated Straw}

The analysis of the typical composition, including cellulose (Kurschner-Hoffner method), lignin (TAPPI T $222 \mathrm{om}-11$ ), and pentosan (TAPPI T $223 \mathrm{~cm}-10$ ), was carried out with referenced standard methods. The analyses were conducted with three repetitions, and the relative standard deviation was below $5 \%$.

The sugar concentrations (cellulose, D-xylose, D-glucose, arabinose) in the pretreated wheat straw were analyzed by a high performance liquid chromatograph (HPLC) (Waters 2695e systems, Waters) equipped with a refractive index detector (Waters 410, Waters) and Aminex HPX-87H anion-exchange column (300 x 7.8 mm, Bio-Rad Corp., Hercules, USA) using $5 \mathrm{mM}$ sulfuric acid as the mobile phase at a flow rate of $0.5 \mathrm{~mL} / \mathrm{min}$. The column temperature was maintained at $50{ }^{\circ} \mathrm{C}$.

After pretreatment with different alkali loadings and reaction times, the composition of the residual straw was measured with at least three repetitions. The dissolved proportions of wheat straw were calculated according to the equations below,

$$
\text { Percent yields }(\%)=\frac{\mathrm{Mr}}{\mathrm{Ms}} \times 100(\%) \quad \text { Compositio } n \text { of the pretreated straw }(\%)=\frac{\mathrm{P}_{\mathrm{Mr}}}{\sum \mathrm{P}_{\mathrm{Mr}}} \times 100(\%)
$$

where $M_{\mathrm{s}}$ is the oven-dry weight of the pretreated straw $(\mathrm{g}), M_{\mathrm{r}}$ is the weight of the components (ash, lignin, cellulose, etc.) of the pretreated straw (g), and $P_{\mathrm{Mr}}$ is the percent yield of the components in the pretreated solid (\%)

Monosaccha ride compositio $\mathrm{n}$ of residual $(\%)=\frac{\text { Monosaccha rides } \mathrm{g} / \mathrm{L}}{\sum \text { Monosaccha ride compositio } \mathrm{ns} \mathrm{g} / \mathrm{L}} \times$ Pretreated solid $\times 100(\%)$

\section{RESULTS AND DISCUSSION}

\section{Composition of the Pretreated Straw}

The percent yields of the components retained in the pretreated straw are displayed in Fig. $2 \mathrm{a}$ as a function of the $\mathrm{NaOH}$ loading for the three different pretreatment times $(1$, 2 , and $3 \mathrm{~h}$ ).

As can be seen in Fig. 2a, the results displayed the expected trend of a decreased retention of solids as the pretreatment time and $\mathrm{NaOH}$ loading increased. When the $\mathrm{NaOH}$ loading was $140 \mathrm{mg} \mathrm{NaOH} / \mathrm{g}$ dry straw or higher, the loss of raw material was around 3\% to $5 \%$, while it was approximately $10 \%$ to $15 \%$ for the $60 \mathrm{mg} \mathrm{NaOH} / \mathrm{g}$ dry straw loading. The alkali pretreatment is a process whereby the alkaline lignin, carbohydrates, ash, and a small amount of extracts are dissolved out. Before the $\mathrm{NaOH}$ loading reached $140 \mathrm{mg}$ 
$\mathrm{NaOH} / \mathrm{g}$ dry straw, the content of cellulose in the pretreated straw was basically stable. The percent yield of cellulose in the pretreated straw only slightly decreased when the $\mathrm{NaOH}$ loading was $180 \mathrm{mg} \mathrm{NaOH} / \mathrm{g}$ dry straw or higher. At the same pretreatment condition, $75 \%$ Klason lignin, $90 \%$ acid soluble lignin, and $50 \%$ pentosan were dissolved out of the raw material.
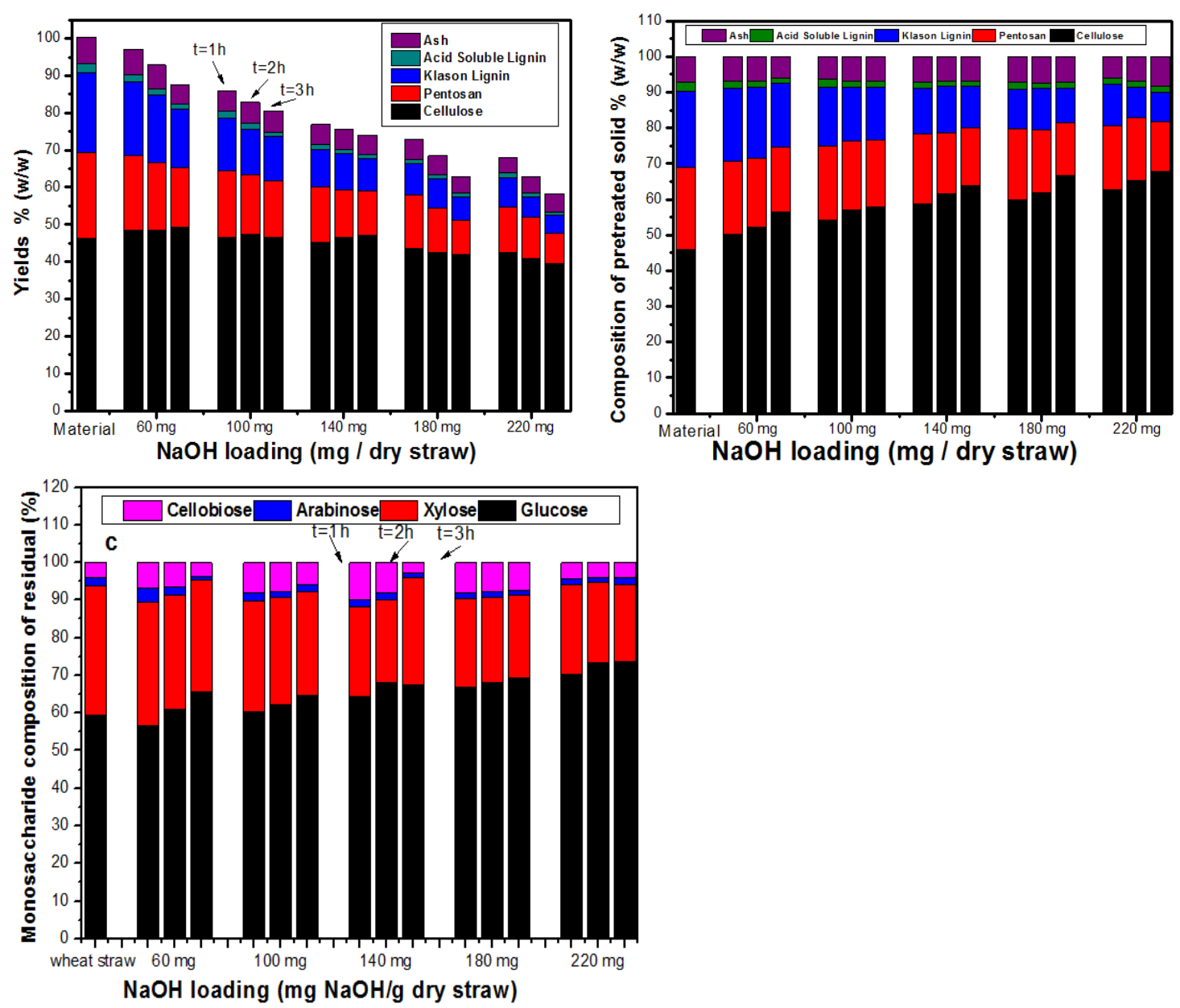

Fig. 2. a) Percent yield of the components in the pretreated straw; b) Composition of the proportions in the pretreated straw; c) Monosaccharide composition of the pretreated straw

As shown in Fig. 2b, the content of alkali-soluble components, such as lignin and pentosans, tended to decrease as the $\mathrm{NaOH}$ loading was increased. Cellulose has relatively stable properties under moderate alkali pretreatment conditions. However, as more lignin and hemicellulose were dissolved in the BL, the proportion of cellulose in the total solution tended to increase as both the $\mathrm{NaOH}$ loading and pretreatment time increased. The total proportions, as can be seen in Fig. 2b, showed the trend of cellulose enrichment present in the pretreated straw. The cellulose content in the pretreated straw increased from $45.3 \%$ to $67.5 \%$. At the same time, the Klason lignin content only accounted for $8.3 \%$ of the pretreated straw, and approximately half of the pentosan was dissolved out of the raw material. The proportion of ash and acid lignin in the pretreated straw showed relatively small changes, with a loss of only $2 \%$ to $3 \%$.

These results indicated that the severity of the pretreatment conditions, especially the alkali loading, had a degradation effect on the cellulose. This effect may have been 
related to a peeling reaction, although the alkali pretreatment at such a low temperature $\left(90{ }^{\circ} \mathrm{C}\right)$ was not enough to cause serious change to the crystal region.

The percentages of monosaccharides shown in Fig. $2 \mathrm{c}$ were derived from the sugar compositional analysis of the residual pretreated straw. From the original sugar compositional analysis of the wheat straw, cellulose accounted for $63 \%$. The alkali pretreatment increased the percentage of cellulose in the pretreated straw, while the percentage of hemicellulose decreased with an increase in the $\mathrm{NaOH}$ loading and pretreatment time. An exceptional result was that the treatment with the lowest alkaline loading (60 mg NaOH/g dry straw) and shortest pretreatment time (1 h) essentially did not affect the proportion of cellulose and hemicellulose. This meant that a mild alkali pretreatment has little effect on the dissolution of carbohydrates. Figure $2 \mathrm{c}$ reflected this, as only less than $10 \%$ of the components dissolved out of the material.

With a longer pretreatment time, more arabinoxylan was dissolved. Simultaneously, the percentage of arabinose present decreased in the rest of the hemicellulose; the decrease was from $5 \%$ at the start to $3 \%$ after $2 \mathrm{~h}$ and $2 \%$ after $3 \mathrm{~h}$. Because arabinose is a branched chain link sugar unit of the arabinoxylan macromolecular chain, it combines with the hydroxy of the main chain to form 1-3 glycosidic bonds, which is a relatively stable connection. The alkali pretreatment at such a low temperature $\left(90{ }^{\circ} \mathrm{C}\right)$ and low $\mathrm{NaOH}$ loading was not enough to break these bonds. Moreover, when the $\mathrm{NaOH}$ loading was $140 \mathrm{mg} \mathrm{NaOH} / \mathrm{g}$ dry straw or higher, the percent of arabinose in the pretreated straw fluctuated in response to the pretreatment time, and its proportion in the pretreated straw stayed at $2 \%$ to $3 \%$. Therefore, the effect of alkali on the selective decomposition of glycosidic bonds in the arabinoxylan and arabinose units was negligible. An increase in the severity of the pretreatment only caused more of the arabinoxylan to dissolve out of the cell walls.

\section{X-Ray Diffraction (XRD) Analysis of the Pretreated Straw}

The wheat straw samples pretreated with 60 to $220 \mathrm{mg} \mathrm{NaOH} / \mathrm{g}$ dry straw for 1,2 , and $3 \mathrm{~h}$ were compared with XRD analysis. The XRD patterns shown in Fig. 3a, 3b, and $3 \mathrm{c}$ were a reflection of the crystalline cellulose structure in the straw. The patterns were essentially the same, except that the height of the peaks at the $2 \theta$ values $18^{\circ}$ and $22.8^{\circ}$ varied for each pretreatment condition. It was easy to see that as the alkali loading and pretreatment time increased, the intensities of the two peaks increased. The only exception was the XRD curve of the straw with a $60 \mathrm{mg} \mathrm{NaOH} / \mathrm{g}$ dry straw loading pretreated for 1 $\mathrm{h}$, which was almost unchanged from that of the untreated straw. The crystallinity was calculated with the area proportion of the total crystalline region, and the relationship between the crystallinity of the samples and alkali dosage is displayed in Fig. 3d. The crystallinity of the samples increased as the alkali amount and pretreatment time increased, which was considered the result of the amorphous matter, such as alkaline-soluble lignin and hemicellulose, being progressively removed from the straw. As a result, the increase in crystallinity corresponded with the elevated level of cellulose in the pretreated straw. As for the effect of the alkali loading on the cellulose in the straw, the possibility of destructive effects from the cellulosic crystal structure was not taken into account because the alkali pretreatment at such a low temperature $\left(90^{\circ} \mathrm{C}\right)$ was not enough to cause severe change to the crystal region, as was already discussed. 

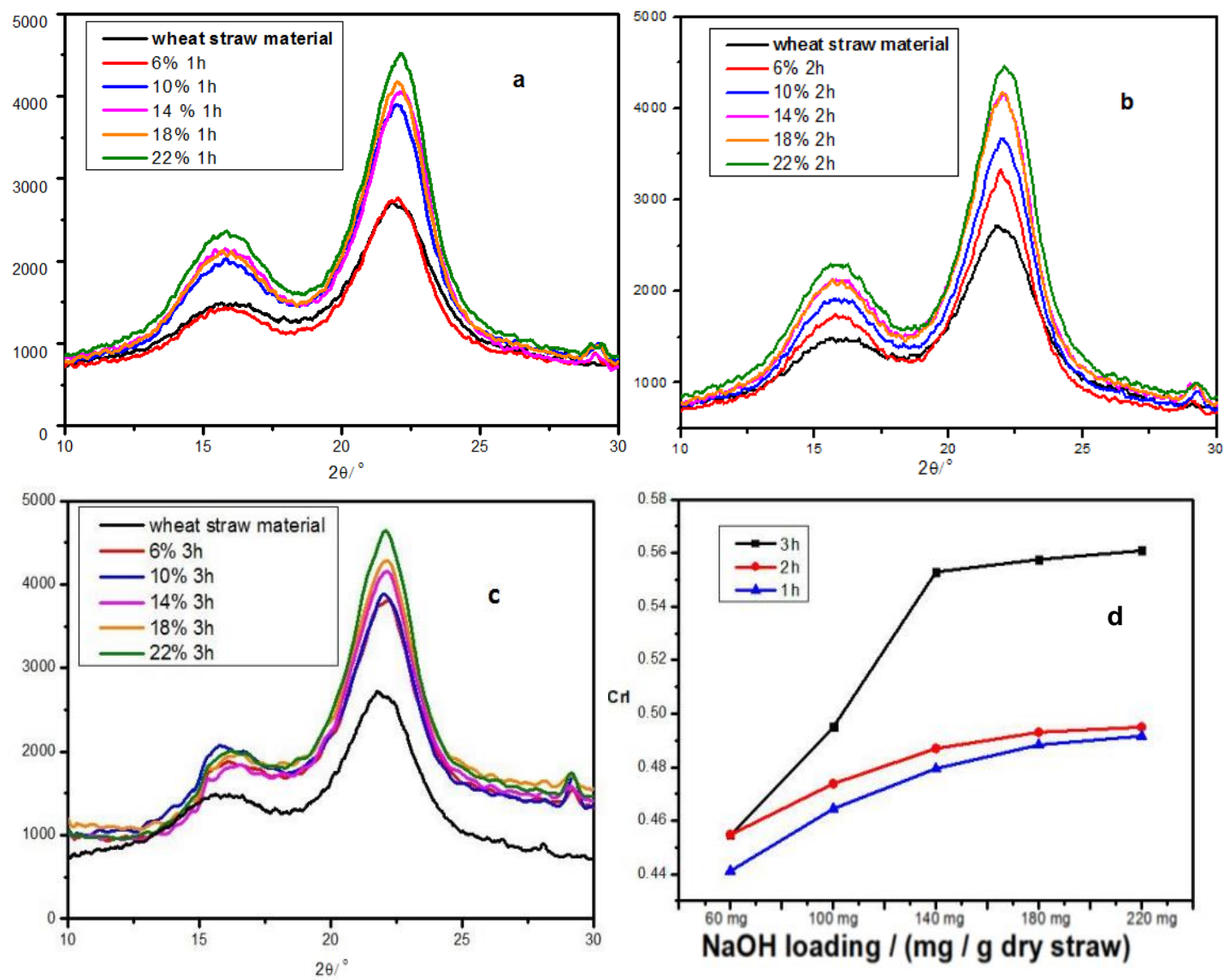

Fig. 3. XRD peaks of the wheat straw pretreated for (a) 1, (b) 2, and (c) $3 \mathrm{~h}$; d) Crystallinity of the pretreated straw as a function of the $\mathrm{NaOH}$ loading and pretreatment time

\section{SEM of the Pretreated Straw}

A great deal of the alkaline-soluble components that exist in wheat straw are well known. Because alkali pretreatment can extract a lot of the soluble matter from the straw, the micro-structure and morphology of the tissue is inevitably influenced. Figure 4 visually displays the photographs of the macro-structure (top row) and micro-structure (bottom two rows) of the original wheat straw and wheat straw pretreated with 60 to $220 \mathrm{mg} \mathrm{NaOH} / \mathrm{g}$ dry straw (from left to right).

It was evident from Fig. 4 that the macro morphological structures became looser as the alkali loading increased. When the $\mathrm{NaOH}$ loading amount was $140 \mathrm{mg} \mathrm{NaOH} / \mathrm{g}$ dry straw, part of the wheat tissue was found to have separated into streaks and fibrous bundles. Subsequently, the higher loadings of alkali increased the amount of separation and the wheat straw became light in color.

It was observed that the tissue that collapsed and became pulp was mainly from the straw leaves. Compared with the leaves, the stem tissue of the straw did not disintegrate easily, even when the alkali loading was $220 \mathrm{mg} \mathrm{NaOH} / \mathrm{g}$ dry straw, and there did not appear to be a distinct color difference between the tissues treated with 60 and $220 \mathrm{mg}$ $\mathrm{NaOH} / \mathrm{g}$ dry straw. This meant that the removal of lignin from the stem was not as easy as removal from the leaves. 

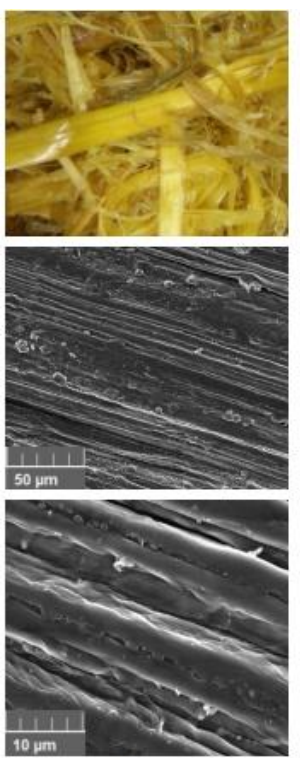

6
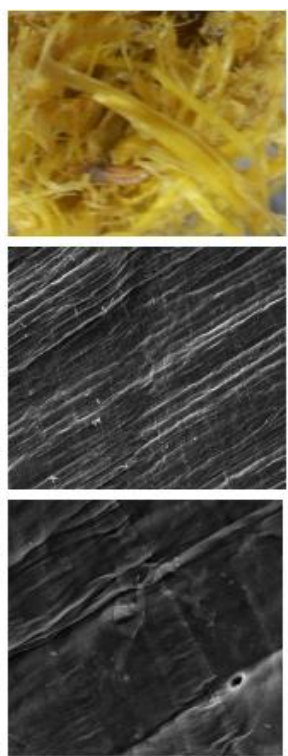

10
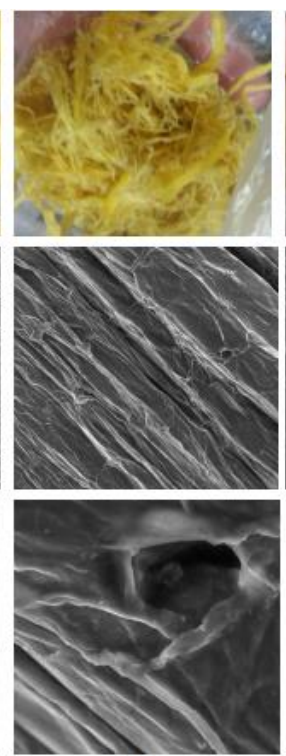

14
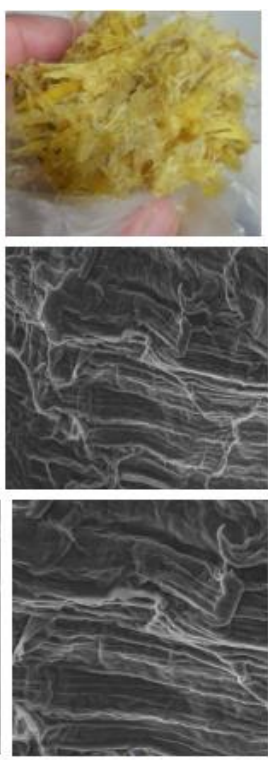

18
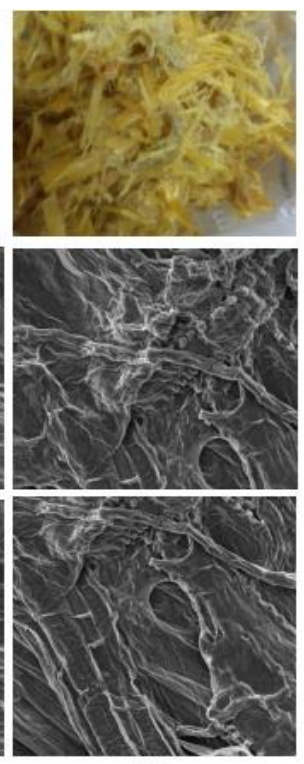

22

Fig. 4. Stereoscopic micrographs (top row) and SEM images (bottom two rows) of the soda-AQ pretreated wheat straw

For the micro-structure of the straw, the original straw and straw pretreated with five different alkali dosages were observed by SEM. Compared with the somewhat obscured surface of the original straw, the venation of the stem vascular bundles became distinctly undulated after pretreatment and were similar to that of the original straw, until the alkali loading was $100 \mathrm{mg} \mathrm{NaOH} / \mathrm{g}$ dry straw. Thereafter, pretreatment with a $140 \mathrm{mg}$ $\mathrm{NaOH} / \mathrm{g}$ dry straw loading caused the compact fibrous bands to become sparse and coarse. This was largely the result of the removal of a considerable amount of soluble components from the straw, and the resulting loosened tissue collapsed, shrank, and adjacent fibrous bands closed-up because of the hydrogen bonding interaction that occurred when the treated straw was air-dried. Furthermore, the original linear fibrous bands appeared deformed, bent, and even curled when the alkali loading was $180 \mathrm{mg} \mathrm{NaOH} / \mathrm{g}$ dry straw or higher. In other words, the pretreatment, even at the low temperature of $90{ }^{\circ} \mathrm{C}$, was able to change the straw structure if the alkali loading was $180 \mathrm{mg} \mathrm{NaOH} / \mathrm{g}$ dry straw or higher, although the straw tissue did not reach the level of fibrous band disaggregation.

The above discussion was concerned with the percentage of solids that were retained after the pretreatment and the physical changes in the carbohydrate portions of the remaining biomass, which demonstrated the dramatic modification of the biomass cell wall structure that took place after lignin removal and rather unremarkable changes in the cellulose crystallinity. It was seen that the alkaline pretreatment at relatively mild conditions was able to remove substantial amounts of lignin from the wheat straw, which could make the plant cell wall polysaccharides much more amenable to digestion by pulping and biomass refining. At the same time, because of the structural changes shown in Fig. 4, the bulk density increased by $20 \%$ to $30 \%$, which is good news for industrial biomass conversion applications.

\section{Composition of the BL}

The BL derived from the pretreated straw had a complex composition. It contained residual alkali, lignin groups, carbohydrates, and more. The dissolved lignin and 
carbohydrates in the BL were extracted by the process given in Fig. 1, and the percentage of these components was calculated with Eq. 2. The residual $\mathrm{NaOH}$ reflected the amount of alkali that reacted with the material, and the lignin and carbohydrates obtained from the $\mathrm{BL}$ at different reaction times represented the process of dissolution.
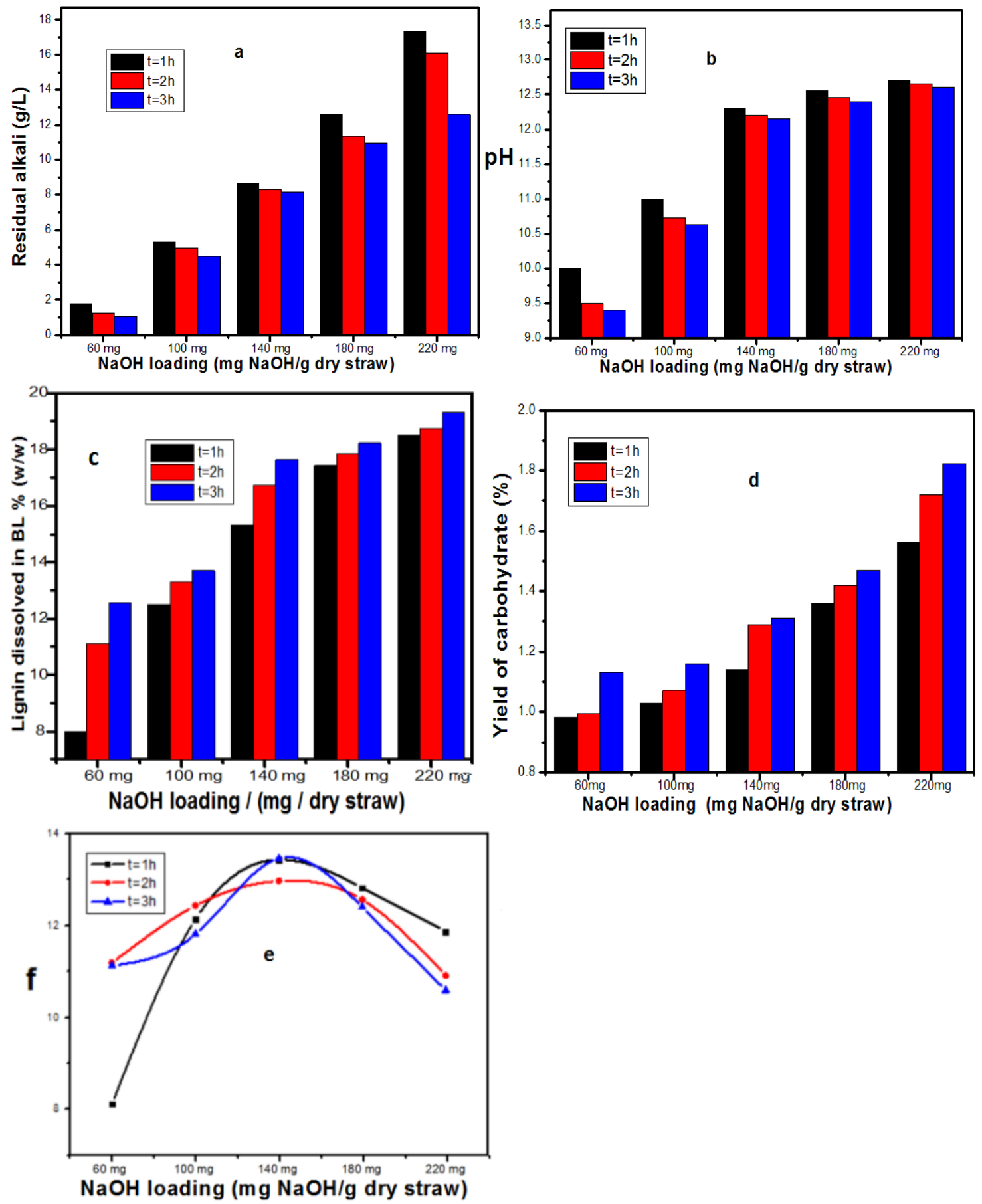

Fig. 5. Composition of the BL: (a) residual alkali, (b) pH, (c) carbohydrates, and (d) lignin; (e) values of the fraction optimization function ( $f$ ) 
As shown in Figs. 5c and 5d, more lignin and carbohydrates were dissolved in the $\mathrm{BL}$ as the $\mathrm{NaOH}$ loading and pretreatment time increased, which was similar to the trend observed for the proportions of the total components in the pretreated straw (seen in Fig. 2a). However, two different components had different dissolution behaviors.

At the lowest $\mathrm{NaOH}$ loading of $60 \mathrm{mg} \mathrm{NaOH} / \mathrm{g}$ dry straw, only approximately $1 \%$ of carbohydrates were dissolved out during the 2-h pretreatment. This may have been a consequence of the fast consumption of alkali in the initial pretreatment stage, such that there was not enough residual alkali to continue the reaction. The dissolution of carbohydrates only occurred on the surface layer, and the pretreated straw retained the structural integrity under this mild condition. However, increasing the pretreatment time to $3 \mathrm{~h}$, the alkali pretreatment was able to soften the internal structure of the straw, as can be seen in Fig. 4, which improved the dissolution of carbohydrates. It was seen that if the pretreatment time was $3 \mathrm{~h}$ and the $\mathrm{NaOH}$ loading was $60 \mathrm{mg} \mathrm{NaOH} / \mathrm{g}$ dry straw, there was a noticeable improvement to the dissolution of carbohydrates.

These results cannot be separated from the serious structural modification of the pretreated straw. When the $\mathrm{NaOH}$ loading was $220 \mathrm{mg} \mathrm{NaOH} / \mathrm{g}$ dry straw and the pretreatment time was $3 \mathrm{~h}, 50 \%$ of the hemicellulose was dissolved in the BL. Compared with the carbohydrates, the dissolution of lignin appeared to be highest at the lowest $\mathrm{NaOH}$ loading (60 $\mathrm{mg} \mathrm{NaOH} / \mathrm{g}$ dry straw). It was inferred from this that lignin can be easily dissolved out with a mild alkali pretreatment, while carbohydrates require more severe pretreatment conditions. As the pretreatment severity increased, the carbohydrate dissolution rate increased exponentially. At the same time, the lignin dissolution reached an equilibrium when the $\mathrm{NaOH}$ loading was $180 \mathrm{mg} \mathrm{NaOH} / \mathrm{g}$ dry straw. It is worth mentioning that the $140 \mathrm{mg} \mathrm{NaOH} / \mathrm{g}$ dry straw loading was the turning point for the equilibrium, as can be seen in Fig. 5e, and the lignin content at this point was the highest. If the goal is to get more dissolution of compounds from the raw material, especially carbohydrates, more $\mathrm{NaOH}$ should be loaded and the pretreatment time should be prolonged. However, a higher addition of alkali and longer pretreatment time is not good for industrial applications because of the low economic efficiency. Therefore, choosing the appropriate alkaline pretreatment depends on the production goal.

\section{Gel Permeation Chromatography (GPC) Analysis}

With analysis of the GPC, the $M_{\mathrm{w}}$ and $M_{\mathrm{n}}$ of carbohydrate and lignin, which were dissolved into the BL, are shown in Fig. 6. As it can be observed, the $M_{\mathrm{w}}$ of the carbohydrate was all above 6000 (about 45 monosaccharide units) and up to 7000 (about 56 monosaccharide units), on a $\mathrm{g} / \mathrm{mole}$ basis, which is three times that of lignin. It is worth pointing out, the $M_{\mathrm{w}}$ and $M_{\mathrm{n}}$ of carbohydrates reach the lowest point at the $140 \mathrm{mg} \mathrm{NaOH}$ / $\mathrm{g}$ dry straw $\mathrm{NaOH}$ loading for $2 \mathrm{~h}$ and the DP of this point is lowest too $(n=1.06)$. Before that point, each $\mathrm{NaOH}$ loading has a lowest peak, when the pretreatment time reaches $2 \mathrm{~h}$. When the alkali loading reached $18 \%$ or greater, and with a prolonged the pretreatment time, the $M_{\mathrm{w}}$ continuously increased. The $M_{\mathrm{w}}$ of the carbohydrate rose to its highest level of 8488 at $220 \mathrm{mg} \mathrm{NaOH} / \mathrm{g}$ dry straw $\mathrm{NaOH}$ loading for $3 \mathrm{~h}$. It can be inferred from this that before the $\mathrm{NaOH}$ loading has reached $140 \mathrm{mg} \mathrm{NaOH} / \mathrm{g}$ dry straw, the group of low molar weight carbohydrates will first dissolve into the BL. The alkali pretreatment at such low temperatures $\left(90^{\circ} \mathrm{C}\right)$ was not enough to cause any conspicuous change of the crystal structure. So, the alkaline effect on the hemicellulose can be ruled out as the basic reason for this. With $\mathrm{NaOH}$ loading reaching $180 \mathrm{mg} \mathrm{NaOH} / \mathrm{g}$ dry straw or more, the larger molar mass can be dissolved into BL because the gaps between the cellulose enlarge and 
more alkaline-soluble groups/material can be removed from the cell wall, and the $M_{\mathrm{w}}$ becomes more dispersed.

The $M_{\mathrm{w}}$ of lignin rose from 1200 at $60 \mathrm{mg} \mathrm{NaOH} / \mathrm{g}$ dry straw $\mathrm{NaOH}$ loading to a maximum of 4500 at $220 \mathrm{mg} \mathrm{NaOH} / \mathrm{g}$ dry straw $\mathrm{NaOH}$ loading. The average molar weight never stopped increasing, while the average molar number reached a gentle peak. This is not hard to see from Fig. 6 (b), before $140 \mathrm{mg} \mathrm{NaOH} / \mathrm{g}$ dry straw $\mathrm{NaOH}$ loading, when pretreated time was $1 \mathrm{~h}$, the $M_{\mathrm{w}}$ of lignin was all below 1500 (about 6 to 8 lignin units). When the pretreatment time was prolonged to $2 \mathrm{~h}$, the $M_{\mathrm{w}}$ of lignin could reach about 2000 (about 10 to 12 lignin units) under $140 \mathrm{mg} \mathrm{NaOH} / \mathrm{g}$ dry straw $\mathrm{NaOH}$ loading. It can be inferred that a weak pretreatment condition (60 mg NaOH / g dry straw) cannot make any alkali-soluble compositions in the straw dissolved into the BL. As shown in Fig. 4, the structure of straw after $60 \mathrm{mg} \mathrm{NaOH} / \mathrm{g}$ dry straw pretreatment remained intact compared with unpretreated straw. This structure is not good for the dissolution of the lignin and carbohydrates. Under prolonged pretreatment, the DP of the $60 \mathrm{mg} \mathrm{NaOH} / \mathrm{g}$ dry straw increased from 1.03 to 1.05 . This light increase reflects that under weak alkali pretreatment conditions, the low molecule weight (LMW) lignin was dissolved out from raw straw in an intermediate mass distribution form. However, when $\mathrm{NaOH}$ loading increased to $10 \%$, the $\mathrm{pH}$ environment of the solution could reach 10.5. Although this condition is moderate for pretreatment, prolonging pretreatment time can also bring about greater dissolution of the lignin groups and thereby effectively soften the wheat straw structure. Special attention should be paid to the fact that polydispersity is increased with $M_{\mathrm{w}}$. When $\mathrm{NaOH}$ loading increased to $180 \mathrm{mg}$ / g dry straw or higher, the $M_{\mathrm{w}}$ of the dissolved lignin in the BL reached 4300 to 4800 . Due to strong severity pretreatment conditions will make high molecular weight lignin groups be dissolved into the BL with a wider distribution. Molecular weight distribution (MWD) could reach 1.8.

From the view of effective utilization of lignin, lignin can be preferably dissolved out of the straw gradually. Two kinds of intermediate $M_{\mathrm{w}}$ lignin could obtained from two pretreatment conditions. Low molecular weight (LMW), $M_{\mathrm{w}}$ ranged from 1700 to 2000 and could be obtained at $60 \mathrm{mg} / \mathrm{g}$ dry straw, and HMW $M_{\mathrm{w}}$ ranged from 4300 to 4800 and could be obtained from $220 \mathrm{mg} / \mathrm{g}$ dry straw $\mathrm{NaOH}$ loading, respectively.
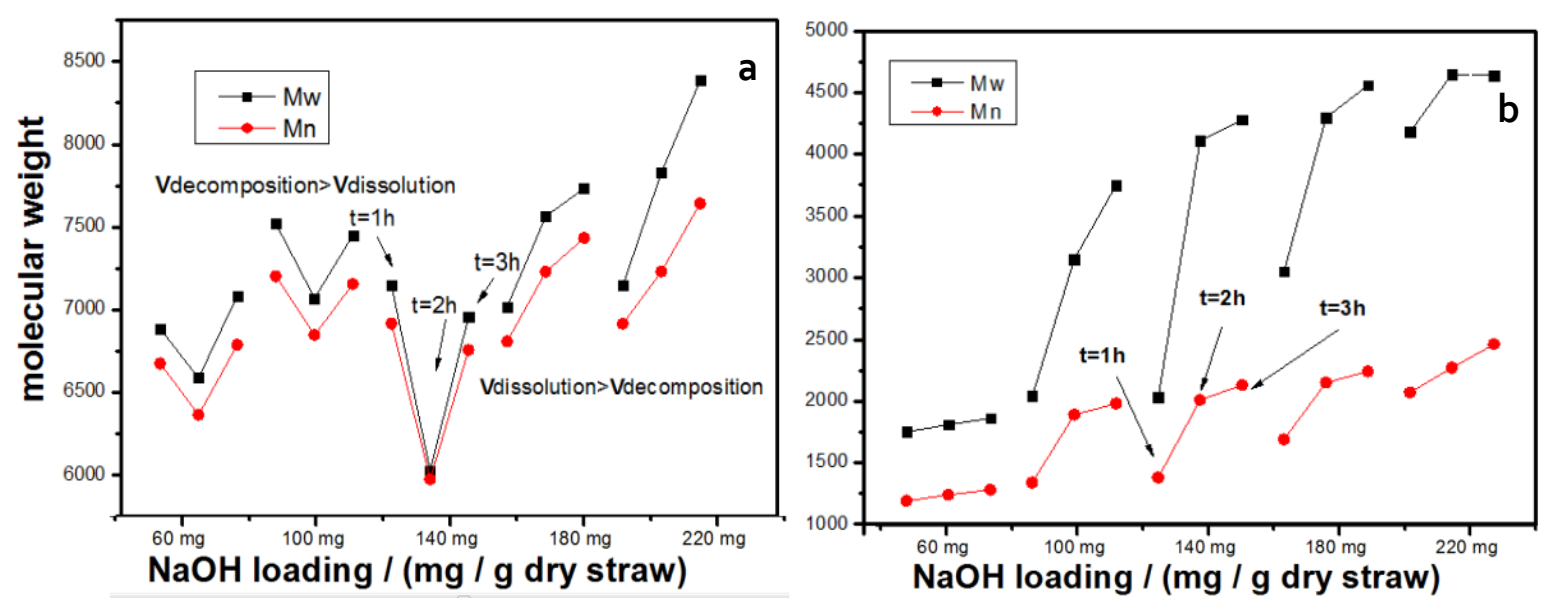

Fig. 6. (a) Weight-average (Mw) and number-average (Mn) molecular weights of the carbohydrate fraction; (b) Mw and Mn of the lignin dissolved in the BL 


\section{CONCLUSIONS}

Low temperature and the addition of anthraquinone (AQ) could protect cellulose from dissolution by alkali, with only a $3 \%$ glucose loss, and 35\% xylan and $75 \%$ lignin dissolution in the black liquor (BL). The BL obtained from the pretreated wheat straw at different pretreatment conditions contained a large fraction of intermediate $M_{\mathrm{w}}$ lignin that could provide a valuable stream for upgrading if technologies can be developed to utilize these species. These results can serve as a guide for the biorefinery industry to optimize lignin removal, while minimizing the loss of carbohydrates during an alkaline pretreatment.

\section{ACKNOWLEDGEMENTS}

This research was supported by the National Natural Science Foundation of China (21276119).

\section{REFERENCES CITED}

Agbor, V. B., Cicek, N., Sparling, R., Berlin, A., and Levin, D. B. (2011). "Biomass pretreatment: Fundamentals toward application," Biotechnol. Adv. 29(6), 675-685. DOI: 10.1016/j.biotechadv.2011.05.005

Baig, K. S., Wu, J., Turcotte, G., and Doan, H. D. (2015). "Novel ozonation technique to delignify wheat straw for biofuel production," Energ. Environ. 26(3), 303-318. DOI: 10.1260/0958-305X.26.3.303

Duan, X., Zhang, C., Ju, X., Li, Q., Chen, S., Wang, J., and Liu, Z. (2013). "Effect of lignocellulosic composition and structure on the bioethanol production from different poplar lines," Bioresource Technol. 140, 363-367. DOI:

10.1016/j.biortech.2013.04.101

Epelde, I. G., Lindgren, C. T., and Lindström, M. E. (1998). "Kinetics of wheat straw delignification in soda and kraft pulping," J. Wood Chem. Technol. 18(1), 69-82. DOI: $10.1080 / 02773819809350126$

FAO (2013). FAO Statistical Yearbook 2013: World Food and Agriculture, Food and Agriculture Organization of the United Nations (FAO), Rome, Italy.

Gao, Y., Wang, H., Guo, J., Peng, P., Zhai, M., and She, D. (2016). "Hydrothermal degradation of hemicelluloses from triploid poplar in hot compressed water at 180 340 C," Polym. Degrad. Stabil. 126, 179-187. DOI:

10.1016/j.polymdegradstab.2016.02.003

Goikhman, A. S., Irklei, V. M., Vavrinyuk, O. S., and Pirogov, V. I. (1992). "X-ray diffraction determination of the degree of crystallinity of cellulose using a computer," Fibre Chem. 24(1), 80-85. DOI: 10.1007/BF00557189

Hassanein, T. F., and Koumanova, B. (2010). "Evaluation of adsorption potential of the agricultural waste wheat straw for basic yellow 21," J. Univ. Chem. Technol. Metallurg. 45(4), 407-414.

Heitner, C., Dimmel, D., and Schmidt, J. (2010). Lignin and Lignans: Advances in Chemistry, Taylor \& Francis, New York, NY.

Karp, E. M., Resch, M. G., Donohoe, B. S., Ciesielski, P. N., O’Brien, M. H., Nill, J. E., Mittal, A., Biddy, M. J., and Beckham, G. T. (2015). "Alkaline pretreatment of 
switchgrass," ACS Sust. Chem. Eng. 3(7), 1479-1491. DOI:

10.1021/acssuschemeng.5b00201

Li, Q., Gao, Y., Wang, H., Li, B., Liu, C., Yu, G., and Mu, X. (2012). “Comparison of different alkali-based pretreatments of corn stover for improving enzymatic saccharification," Bioresource Technol. 125, 193-199. DOI: 10.1016/j.biortech.2012.08.095

Li, C., Zhao, X., Wang, A., Huber, G. W., and Zhang, T. (2015). "Catalytic transformation of lignin for the production of chemicals and fuels," Chem. Rev. 115(21), 11559-11624. DOI: 10.1021/acs.chemrev.5b00155

Lyckeskog, H. N., Mattsson, C., Åmand, L.-E., Olausson, L., Andersson, S.-I., Vamling, L., and Theliander, H. (2016). "Storage stability of bio-oils derived from the catalytic conversion of softwood kraft lignin in subcritical water," Energ. Fuel. 30(4), 30973106. DOI: 10.1021/acs.energyfuels.6b00087

Meek, N., Penumadu, D., Hosseinaei, O., Harper, D., Young, S., and Rials, T. (2016). "Synthesis and characterization of lignin carbon fiber and composites," Compos. Sci. Technol. 137, 60-68. DOI: 10.1016/j.compscitech.2016.10.016

Mittal, A., Katahira, R., Himmel, M. E., and Johnson, D. K. (2011). "Effects of alkaline or liquid-ammonia treatment on crystalline cellulose: Changes in crystalline structure and effects on enzymatic digestibility," Biotechnol. Biofuels 4, 1-16. DOI: 10.1186/1754-6834-4-41

Rios, O., Martha, S. K., Mcguire, M. A., Tenhaeff, W., More, K., Daniel, C., and Nanda, J. (2014). "Monolithic composite electrodes comprising silicon nanoparticles embedded in lignin-derived carbon fibers for lithium-ion batteries," Energ. Technol. 2(9-10), 773-777. DOI: 10.1002/ente.201402049

Sewalt, V. J. H., Beauchemin, K. A., Rode, L. M., Acharya, S., and Baron, V. S. (1997). "Lignin impact on fiber degradation. IV. Enzymatic saccharification and in vitro digestibility of alfalfa and grasses following selective solvent delignification," Bioresource Technol. 61(3), 199-206. DOI: 10.1016/S0960-8524(97)00065-5

Singh, R., Prakash, A., Dhiman, S. K., Balagurumurthy, B., Arora, A. K., Puri, S. K., and Bhaskar, T. (2014). "Hydrothermal conversion of lignin to substituted phenols and aromatic ethers," Bioresource Technol. 165, 319-322. DOI:

10.1016/j.biortech.2014.02.076

Srinorakutara, T., Suttikul, S., and Boonvitthya, N. (2013). "Effect of different pretreatment methods on enzymatic saccharification and ethanol production from sugarcane shoots and leaves," J. Food Sci. Eng. 3(6), 309-316.

Sun, X., Huang, C., Xue, Z., Yan, C., and Mu, T. (2015). "Efficient and sustainable strategy for the hierarchical separation of lignin-based compounds using ionic liquid/compressed $\mathrm{CO}_{2}$," Energ. Fuel. 29(4), 2564-2570. DOI: 10.1021/acs.energyfuels.5b00334

TAPPI T 222 om-11 (2010). “Acid-insoluble lignin in wood and pulp," Technical Association of the Pulp and Paper Industry, Atlanta, USA.

TAPPI T 223 cm-10 (2010). "Pentosans in wood and pulp," Technical Association of the Pulp and Paper Industry, Atlanta, USA.

Zhao, Z., Cannon, F. S., Nieto-Delgado, C., and Pena, L. (2016). "Lignin/collagen hybrid biomaterials as binder substitute for specialty graphites and electrodes," Carbon 108, 303-317. DOI: 10.1016/j.carbon.2016.0.026

Zhan, H.-y. (2010). "Supply and utilization of non-wood fibers and waste papers in China's paper industry," China Pulp \& Paper 29(8), 56-64. 
Zhang, L., and Chen, K. (2017). "Pyrolysis behavior of the black liquor derived from soda-anthraquinone and soda-oxygen pulping of rice straw at different reaction end points," Energ. Fuel. 31(1), 514-522. DOI: 10.1021/acs.energyfuels.6b01735

Zhang, Q., Huang, J., and Yu, G. (2008). "Polychlorinated dibenzo-p-dioxins and dibenzofurans emissions from open burning of crop residues in China between 1997 and 2004," Environ. Pollut. 151(1), 39-46. DOI: 10.1016/j.envpol.2007.03.011

Zhang, J., Ma, X., Yu, J., Zhang, X., and Tan, T. (2011). "The effects of four different pretreatments on enzymatic hydrolysis of sweet sorghum bagasse," Bioresource Technol. 102(6), 4585-4589. DOI: 10.1016/j.biortech.2010.12.093

Article submitted: July 2, 2017; Peer review completed: September 17, 2017; Revised version received and accepted: September 25, 2017; Published: September 28, 2017.

DOI: $10.15376 /$ biores. $12.4 .8550-8564$ 